\title{
Enhancement of the Click Chemistry for the Inverse Diels Alder Technology by Functionalization of Amide-Based Monomers
}

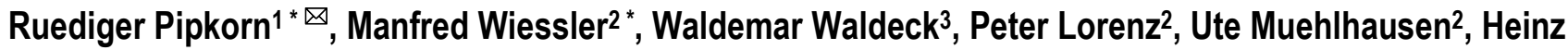 \\ Fleischhacker2, Mario Koch ${ }^{1}$, Klaus Braun²
}

1. German Cancer Research Center, Central Peptide Synthesis Unit, INF 580, 69120 Heidelberg, Germany

2. German Cancer Research Center, Dept. of Imaging and Radiooncology, INF 280, 69120 Heidelberg, Germany

3. German Cancer Research Center, Division of Biophysics of Macromolecules, INF 580, 69120 Heidelberg, Germany

* Ruediger Pipkorn and Mannfred Wiessler have contributed equally to the publication

$\triangle$ Corresponding author: Dr. Rüdiger Pipkorn, German Cancer Research Center (DKFZ), Central Peptide Synthesis Unit, Im Neuenheimer Feld 580, D-69120 Heidelberg, Germany. Phone: +49 6221-42 2847; Fax: +49 6221-42 2846; e-mail: r.pipkorn@dkfz.de

(C) Ivyspring International Publisher. This is an open-access article distributed under the terms of the Creative Commons License (http://creativecommons.org/ licenses/by-nc-nd/3.0/). Reproduction is permitted for personal, noncommercial use, provided that the article is in whole, unmodified, and properly cited.

Received: 2011.03.16; Accepted: 2011.06.16; Published: 2011.06.21

\begin{abstract}
In the near future personalized medicine with nucleic acids will play a key role in molecular diagnostics and therapy, which require new properties of the nucleic acids, like stability against enzymatic degradation. Here we demonstrate that the replacement of nucleobases with PNA by functional molecules harbouring either a dienophile or a diene reactivity is feasible and confers all new options for functionalization. These newly developed derivatives allow independent multi-ligations of multi-faceted components by use of the inverse Diels Alder technology. The high chemical stability and the ease of synthesis qualify these polyamide building blocks as favourites for intracellular delivery and targeting applications. This allows local drug concentrations sufficient for imaging and therapy and simultaneously a reduction of the application doses. It is important to point out that this technology is not restricted to ligation of medicament material; it is also a candidate to develop new and highly efficient active compounds for a "sustainable pharmacy".
\end{abstract}

Key words: Click Chemistry; Diels Alder Reactioninverse (DARinv); local concentration; Peptide Nucleic Acid (PNA); PNA building block functionalization; Sustainable Pharmacy

\section{Introduction}

"Old fashioned" drugs are highly active, but their lack of specificity and sensitivity needs high doses of application correlating with adverse reactions. The differentiation between tumorigenic and the surrounding healthy tissue is hardly possible. Whereas old drugs enter the cells by diffusion, the transfer of nucleic acid drugs across cell membrane is very poor and insufficient. Modern drugs and diagnostics overcome the mentioned handicaps. Therefore a carrier system is indispensable for facilitating the transport of nucleic acid based drugs and imaging and therapy components across the cell membrane. Considerations for the improved membrane transport resulted in a series of procedures. The question respecting the low stability of nucleic acids in biological systems led to the development of numerous DNA analogues possessing higher stability.

Also important was the search for methods to 
connect the carrier molecules to the therapeutic DNA derivatives or/and to the intracellular contrast agents (CA) dedicated for imaging of cellular metabolic processes, combined with image-guided therapeutic approaches.

For the development of modern drugs, a very efficient ligation methodology is the Diels Alder Reaction (DAR) which traces back to 1948 and its potential and the synthesis's mechanisms are well documented [1-3]. The DAR with inverse-electron-demand $\left(\mathrm{DAR}_{\text {inv }}\right)$ was first described almost 10 years later [4-7]. It is characterized by the rapid reaction rates, complete chemical reaction, lack of reverse reaction, chemical reaction at room temperature, and no need for a catalyst. Therefore the $\mathrm{DAR}_{\text {inv }}$ can be considered as a suitable ligation technology. Here we developed monomers based on the peptide nucleic acid's (PNA) polyamide backbone [8], mimicking exactly the Watson-Crick hydrogen-bond formation [9-14]. The functionalization of the "PNA" like amide backbone with imaging molecules suggests a new class of efficient tools suitable for Molecular Imaging and molecular therapeutics not restricted to the classical antisense and antigenic approaches.

Here we present the synthesis of polyamide backbone pentamers and heptamers ligated with the $\mathrm{DAR}_{\text {inv }}$ reaction partners, fulfilling the above mentioned needs. Indeed we like to emphasize that the chemical procedures are documented [15] but in order to achieve a better understanding, the precise steps of the different chemical procedures are described particularly with full details to permit the development of modern therapeutic drugs and diagnostic molecules.

\section{Chemical Procedures}

1. Pentenoic acid chloride and cyclopentene carboxylic acid chloride were purchased from Sigma Aldrich, Germany. The synthesis of the Reppe Anhydride was carried out as documented by Reppe [16]. The reaction to tetracyclo-[5.4.2 $\left.2^{1,7} \cdot \mathrm{O}^{2,6} \cdot \mathrm{O}^{8,11}\right] 3,5$-dioxo-4-aza-9,12-tridecadiene 4 -yl acetyl acid chloride is described by Wiessler [15].

2. The syntheses of the amide backbone monomers (PNA-like but without nucleobase). All syn- thesis steps of the tested Fmoc-protected building blocks were performed according Atherton's and Sheppard's [17] and Wiessler's documentations (Figure 1) [15].

3. The synthesis of the tetrazine dicarbonic acid derivate was performed as described by [15]. The synthesis procedure of the corresponding dansyl derivative was carried out according to the following protocol (Figure 2):

$10 \mathrm{mmol}$ (1.48 g) 2-cyano-nicotinic acid 4 and 5 $\mathrm{ml}$ of hydrazine (at least $80 \%$ ) were heated in an oil bath for $30 \mathrm{~min}$. Between 80 and $90^{\circ} \mathrm{C}$ the evolution of ammonia starts and the material in the flask solidified and turned to orange. After cooling to $20^{\circ} \mathrm{C}$ the material was broken up and washed with $2 \mathrm{~N}$ sulfuric acid, followed by water and acetone. The bis2,6-[5-carboxylic acid-pyrid-2-yl]-dihydrotetrazine 5 (orange colored) could not be purified by recrystallisation but was pure enough for the oxidation step. The yield was 60 to $80 \%$. The tetrazine 6 was suspended in acetic acid and concentrated nitric acid was added dropwise. The colour of the solution immediately turned pink and the tetrazine 6 precipitated. After filtration the pink material was thoroughly washed with acetic acid, followed by acetone and ether.

$2 \mathrm{mmol}$ dicarbonic acid 6 was suspended in 20 $\mathrm{ml}$ thionylchloride and refluxed for ten hours. After that time nearly all the material was dissolved. After evaporation the acid chloride was washed 3 times with toluene, followed by ether. The acid chloride was suspended in $50 \mathrm{ml}$ chloroform, cooled to $0^{\circ} \mathrm{C}$ and a mixture of $2.2 \mathrm{mmol}$ dansyl derivative [19] and 2 mmol N-ethyl-diisoproylamine in $20 \mathrm{ml}$ chloroform were slowly added by a dripping tunnel. After 4 hours at $25^{\circ} \mathrm{C}$ the pink-colored solution was washed with water and dried with sodium sulfate. After evaporation of the solvent the product 7 was purified by a silicagel column chromatography (chloroform/ EtOH 95/5) and recrystallized from aceton. The yield was $50-70 \%$ of deep orange-colored crystals. Mass spectrum MW 874.3: $\mathrm{m} /$ e $897.3(+\mathrm{Na})$ pos. modus and $\mathrm{m} / \mathrm{e} 873.3$ neg.

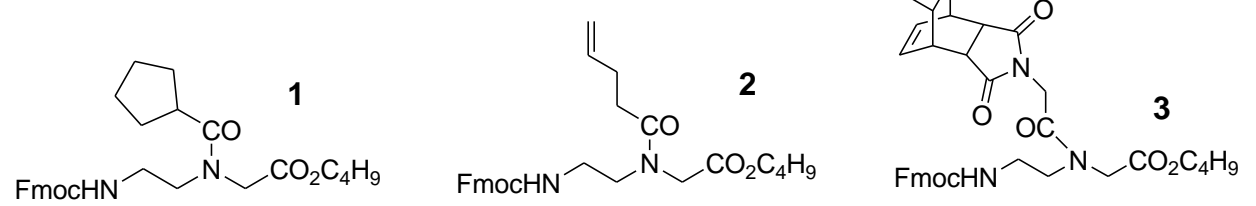

Figure 1 illustrates the amide-based building blocks Fmoc-N-protected glycine-tert-butylester cyclopentane 1, butene 2, and Reppe anhydride 3 derivatized respectively. The synthesis of these was performed according the general procedure for the reaction of the Fmoc-glycine with acid chlorides published by Thomson [18]. 


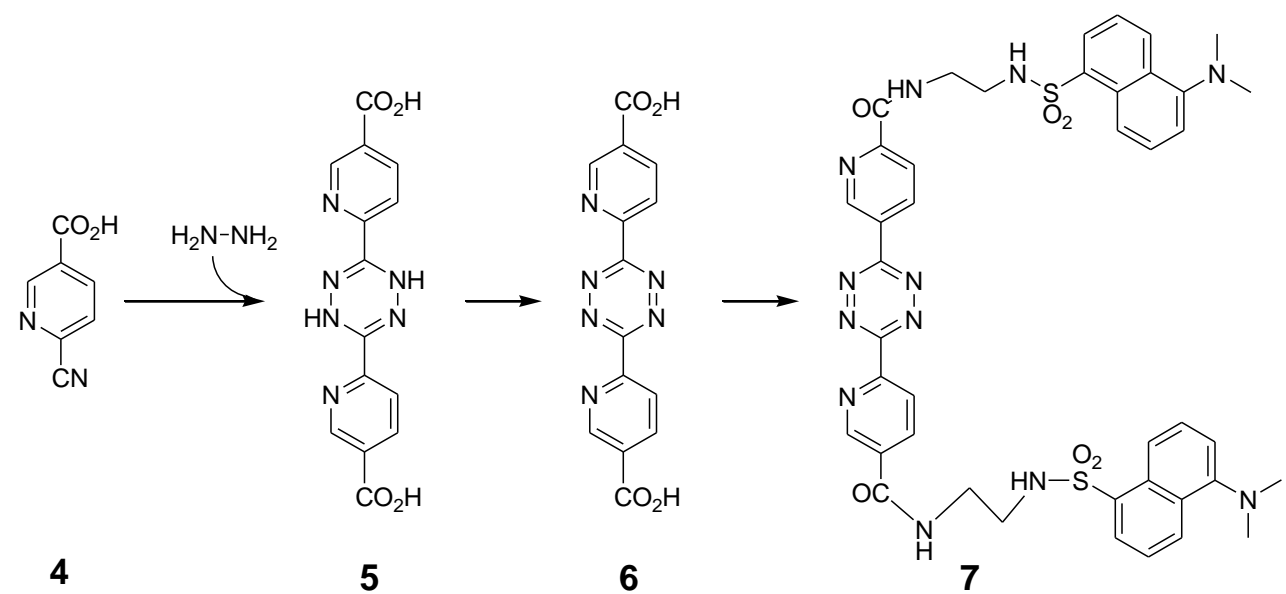

Figure 2 demonstrates the chemical reaction of the 2-cyano-nicotinic acid 4 with hydrazine to 5 . After oxidation the dihydrotetrazine product bis-2,6-[5-carboxylic acid-pyrid-2-yl]-dihydrotetrazine 5 was transformed to the corresponding tetrazine 6 , which in turn reacts with a mixture of the dansyl derivative and the $\mathrm{N}$-ethyl-diisoproylamine and the dansyl sulfamidoethylamine to the tetrazine product 7 linked with 5-dansyl sulfamidoethylcarboxamide-2-yl.

4. For the syntheses of the polyamide-based pentamers I-III (Figure 3, Figure 4) and the heptamer (the ligation product 15 is shown in Figure 7) the solid phase peptide syntheses and the protection group strategies were used as introduced by Merriefield [20] and Carpino [21] considered as general procedure:

To perform the solid phase peptide synthesis (SPPS) [20] of amide modules we employed the Fmoc-strategy [21] in a fully automated peptide synthesizer A433 (Perkin Elmer). The synthesis was carried out on a $0.05 \mathrm{mmol}$ Tenta Gel R Ram (Rapp Polymere) $0.19 \mathrm{mmol} / \mathrm{g}$ by substitution. As coupling agent 2-(1H-Benzotriazole-1-yl)-1,1,3,3-tetramethyluronium hexafluorophosphate (HBTU) was used. A typical synthetic cycle consisted of a single 30 minute coupling step of 3 equivalents of monomers to the growing polyamide chain, followed by capping of the unreacted free amines with acetic anhydride. The protected polyamide resins were treated with $20 \%$ piperidine in dimethylforamide over 5 minutes and then washed thoroughly with dimethylformamide. Cleavage and deprotection of the resins were made by treatment with $90 \%$ trifluoroacetic acid and $10 \%$ triethylsilane.

5. Solid phase synthesis of the Reppe Anhydride polyamide pentamer $I$. To demonstrate the

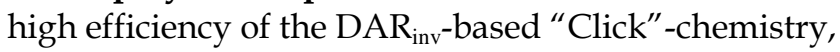
we synthesized a pentamer which is amide-based and functionalized with the "Reppe Anhydride" 8 as shown in Figure 3: Mass spectrum: m/e 1723.3 calc. 1722.7. The corresponding ESI MS is shown in the Figure S3.

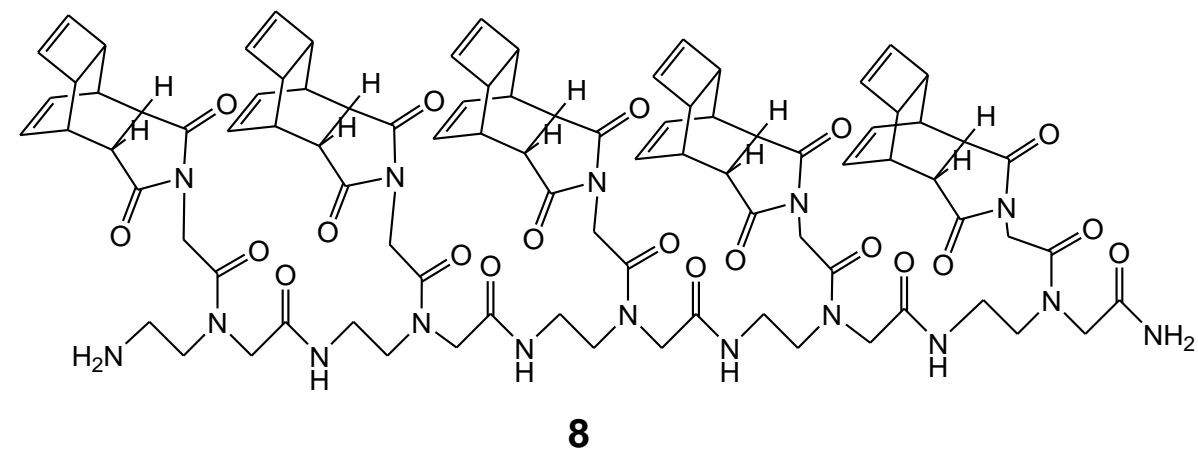

Figure 3 exemplifies the chemical structure of the pentamer consisting of the "Reppe Anhydride" derivative 8. 


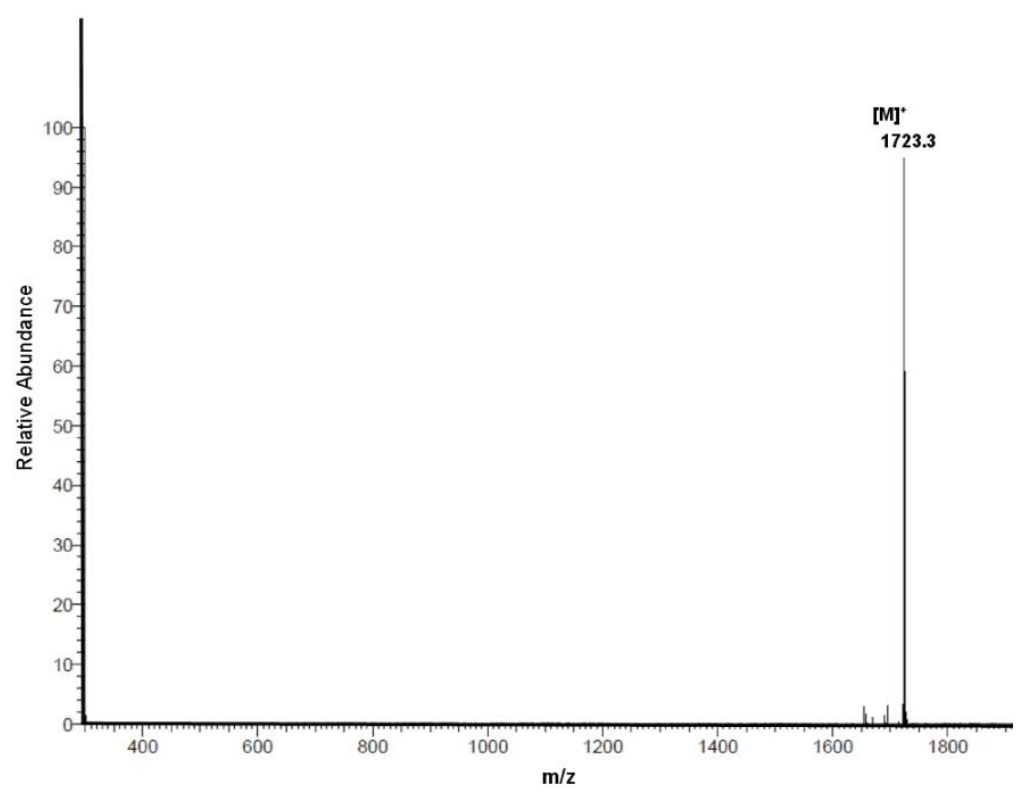

Figure S3 ESI MS of 8.

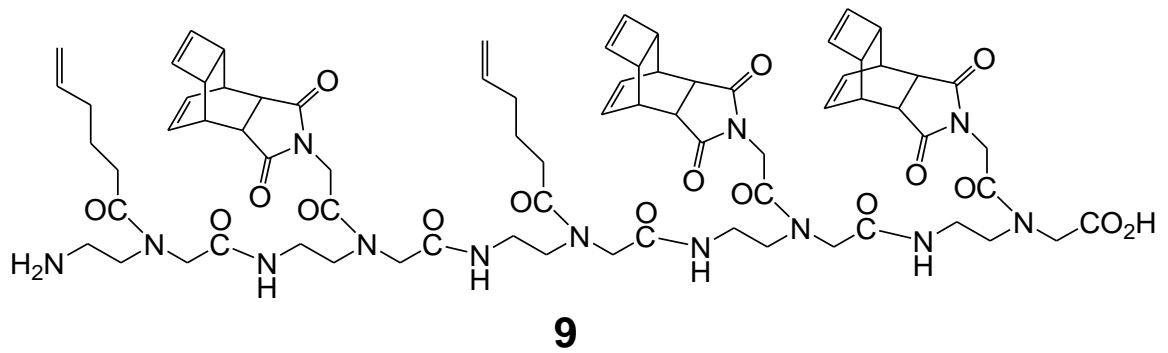

Figure 4 the scheme exemplifies the amide backbone-based pentamer 9 consisting of three Reppe Anhydride monomers 3 and two pentenoic acid 2 building blocks.

SPPS of the pentenoyl-pentamers II \& the mixed Reppe Anhydride pentamers III: We also produced mixed pentamers composed of the Reppe Anhydride building block 3 (m/e 928.3 calc. 927.5) and of the pentenoic acid 2 building block 2. (Mass spectrum: 1667.5, calc. 1665.9) for chemical reaction by the solid phase peptide synthesis. (Figure 4)

9. Ligation of the pentamer $I$ with the tetrazine-dicarboxylate 6: One $\mu \mathrm{mol}$ of the pentamer I 8 (Figure 3) and $5.5 \mu \mathrm{mol}$ of the tetrazine 6 (intermediate as shown in Figure 2) [22] were mixed in $0.5 \mathrm{ml}$ chloroform. After $10 \mathrm{~min}$ the red colour disappeared. After $30 \mathrm{~min}$ the solvent was evaporated. Mass spectrum calc. 2573.9 found m/e 1288.5 for the dication. No signal was found for the 4 -fold adduct. By using 5 $\mu \mathrm{mol}$ of the tetrazine 6 the 4 -fold adduct could be seen after $30 \mathrm{~min}$ in the mass spectrum.
10. Ligation of the pentamer I with the dansyl-tetrazine 7: One $\mu \mathrm{mol}(1.72 \mathrm{mg})$ pentamer I 8 (Figure 3) and $5.5 \mu \mathrm{mol}(4.81 \mathrm{mg}) 7$ (the reaction product is shown in Figure 2) were reacted in $0.5 \mathrm{ml}$ DMSO for 12 hours. The mass spectrum showed the product at $\mathrm{m} / \mathrm{e} 5958.9$ calc. 5958.1 , the trication at $\mathrm{m} / \mathrm{e}$ 1986.5 and the tetracation at 1489. The dansyl-tetrazine could be seen at $\mathrm{m} / \mathrm{e} 875.7$.

11. Ligation of the Pentamer II with the tetrazine-dicarboxilate 6: The $\mathrm{DAR}_{\mathrm{inv}}$ of the pentenoyl-pentamer II 2 with tetrazine-3,6-dimethylcarboxilate $2 \mu \mathrm{mol}(1.86 \mathrm{mg})$ of the pentamer 8 and $10 \mu \mathrm{mol}(2 \mathrm{mg})$ of the tetrazine 6 in $0.5 \mathrm{ml}$ chloroform were reacted for $12 \mathrm{hrs}$. The mass spectrum showed the 5 -fold adducts at m/e 1779.0 calc. 1778.4, the dication at $\mathrm{m} / \mathrm{e} 890.0$. At $\mathrm{m} / \mathrm{e} 1608.9$ a weak signal appeared for the 4 -fold adduct. 
12. Ligation of Pentamer II with the dansyl-tetrazine 7. Two $\mu$ moles $(1.86 \mathrm{mg})$ of the pentamer II (Figure 4) and $10 \mathrm{mmol}(8.8 \mathrm{mg}$ ) of the dansyl-tetrazine 7 were dissolved in $0.5 \mathrm{ml}$ chloroform/DMSO and reacted for 24 hours. The mass spectrum showed m/e 5160.1 calc. 5162.9 for the 5-fold adduct, m/e 4312.9 calc 4315.6 for the 4 -fold and $\mathrm{m} / \mathrm{e} 3466.9$ calc. 3469.3 for the 3 -fold adduct.

13. Ligation reaction of a polyamide heptamer III functionalized with different reactive dienophiles with two different tetrazines. The sequence of the ligations reactions A and B are shown in Figure 7.

A. $1.66 \mathrm{mg}(1 \mu \mathrm{mol})$ of the polyamide heptamer were pre-filled and reacted with $0.396 \mathrm{mg}(2.0 \mu \mathrm{mol})$ of dimethyl-1,2,4,5-tetrazine-3,6-dicarboxylate 6 dissolved in $0.5 \mathrm{ml}$ dichloromethane .Under stirring the reaction vessel was kept until the decolorization was complete in about $10 \mathrm{~min}$.

The mass spectrum of the 2-fold adduct was at $\mathrm{m} / \mathrm{e} 2008.7$ calc. 2007.0 and the dication at m/e 1004.9. The 3 -fold adduct could be seen as dication at $\mathrm{m} / \mathrm{e}$ 1090.0 calc. 1089.5 .

B. In a second step the above mentioned probe was reacted with $1 \mu \mathrm{mol}(0.87 \mathrm{mg})$ of the dansyltetrazine solved in a few drops of DMSO. The reaction was completed over night. In the mass spectrum the product can be seen as dication at $\mathrm{m} / \mathrm{e} 1428.8$, corresponding to MW 2855.6; calc. 2853.2.

\section{Ligation Results}

Our amide building blocks, deriving from PNA devices work in a variety of ligation areas as illustrated in the following:

Using the solid phase peptide synthesis (SPPS) we could manufacture functional and modularly composed polyamides for coupling different active agents. These could be used either in parallel as imaging molecules or in combination with transporter molecules in order to reach local concentrations which were unachievable until now.

The synthesized pentamer 8 consisting of five amide-based backbone functionalized with the Reppe Anhydride derivative $\mathbf{3}$ acts as a cargo and is the reaction partner, (a dienophile compound) for substances harbouring diene reaction groups. The following features predispose the amide based building block functionalized with the "Reppe Anhydride" derivative for successful use in the DAR inv chemistry [16].

The well controlled different reactivity of the pentenoyl group compared with the dienophile groups in the amide based monomer functionalized with the "Reppe Anhydride" allows the synthesis of polyamide oligomers consisting of two or more different dienophiles suitable for two or more independent Diels Alder Reactions with inverse-electron-demand $\left(D_{A} R_{\text {inv }}\right)$ as shown exemplarily in Figure 4.

\section{$\mathrm{DAR}_{\text {inv }}$ ligation of the tetrazine derivatized pol- yamide pentamers}

The scheme 6 describes the polyamide pentamer molecule after the complete ligation by the $\mathrm{DAR}_{\mathrm{inv}}$ (shortened to the reaction site). Details of the chemical reaction are documented by Wiessler [23].

\section{Ligation of the (RE-PA) 5 with dime- thyl-1,2,4,5-tetrazine-3,6-dicarboxylate}

The first highly active part of the construct, allows the ligation of e.g. carrier molecules on the desired side of the molecule. The second dienophile on the other side with lower reactivity is available for further selective functionalizations under different reaction conditions e.g. acting as coupling side for fluorescent markers.

\section{Ligation of the (RE-PA) 5 pentamer with the di- dansyl-diaryl-tetrazine}

This $\mathrm{DAR}_{\text {inv }}$ mediated reaction describes the final product $\mathbf{1 0}$ of the complete ligation of the Reppe Anhydride pentamer with the dimethyl-1,2,4,5-tetrazine-3,6-dicarboxylate functionalized with two dansyl chlorides resulting in a symmetric molecule as illustrated in Figure 6.

\section{Ligation reaction of a polyamide heptamer functionalized with different reactive dieno- philes}

A ligation of a polyamide heptamer 12 consisting of different reactive dienophiles like the Reppe Anhydride" derivative $\mathbf{3}$ and the pentenoic acid $\mathbf{2}$ is shown in Figure 1. They could also be separated by a cyclopentane building block 1 , which avoids possible steric interactions restricting the ligation efficiency. The ligation starts with the chemical reaction of the Reppe Anhydride derivative monomer 3, the reaction partner with the higher reactivity. After completion, the second ligation reaction with the pentenoic acid 2 begins. The process of the chemical reaction can be monitored by the colour change and the end of the reaction is indicated by decolorization after few minutes. 


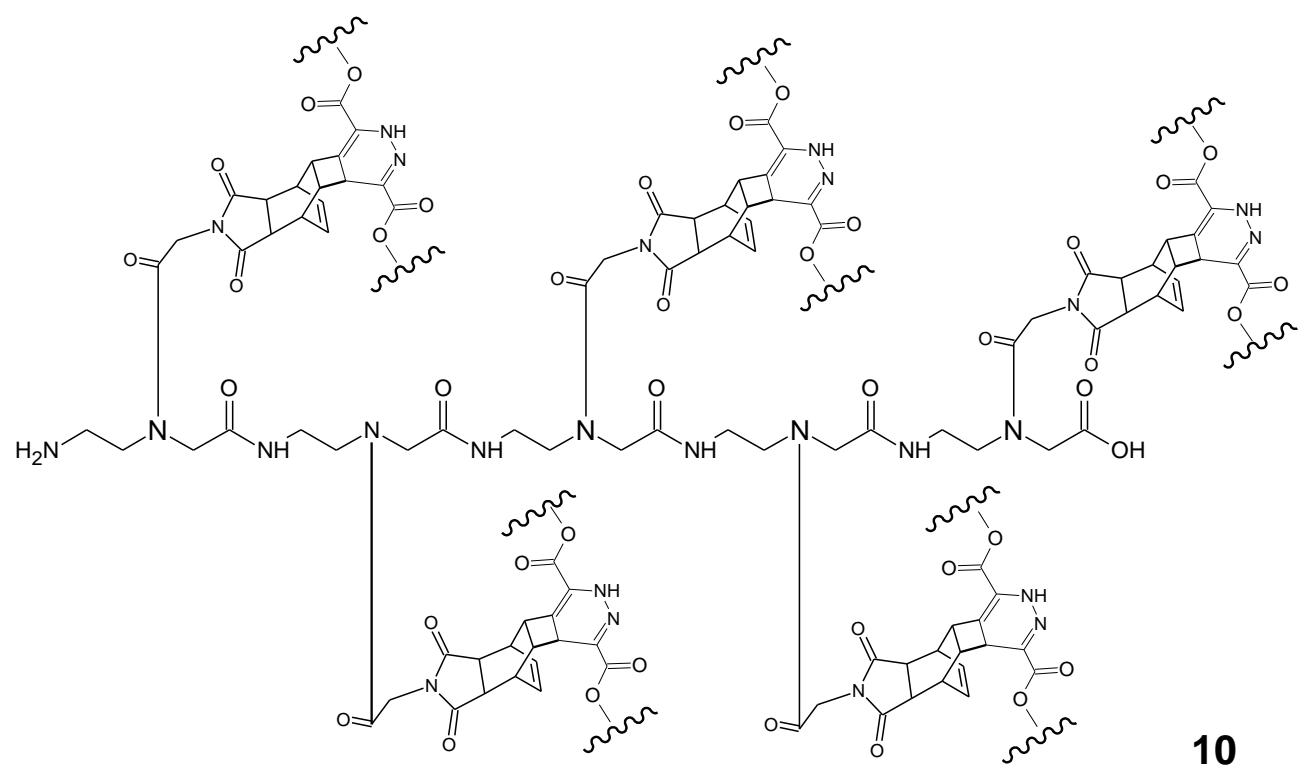

Figure 5 shows the amide backbone-based pentamer Reppe Anhydride derivative functionalized after $D A R_{\text {inv }}$ mediated ligation with dimethyl-1,2,4,5-tetrazine-3,6-dicarboxylate 10 . The $\mathrm{DAR}_{\mathrm{inv}}$ mechanism is described in detail [5].

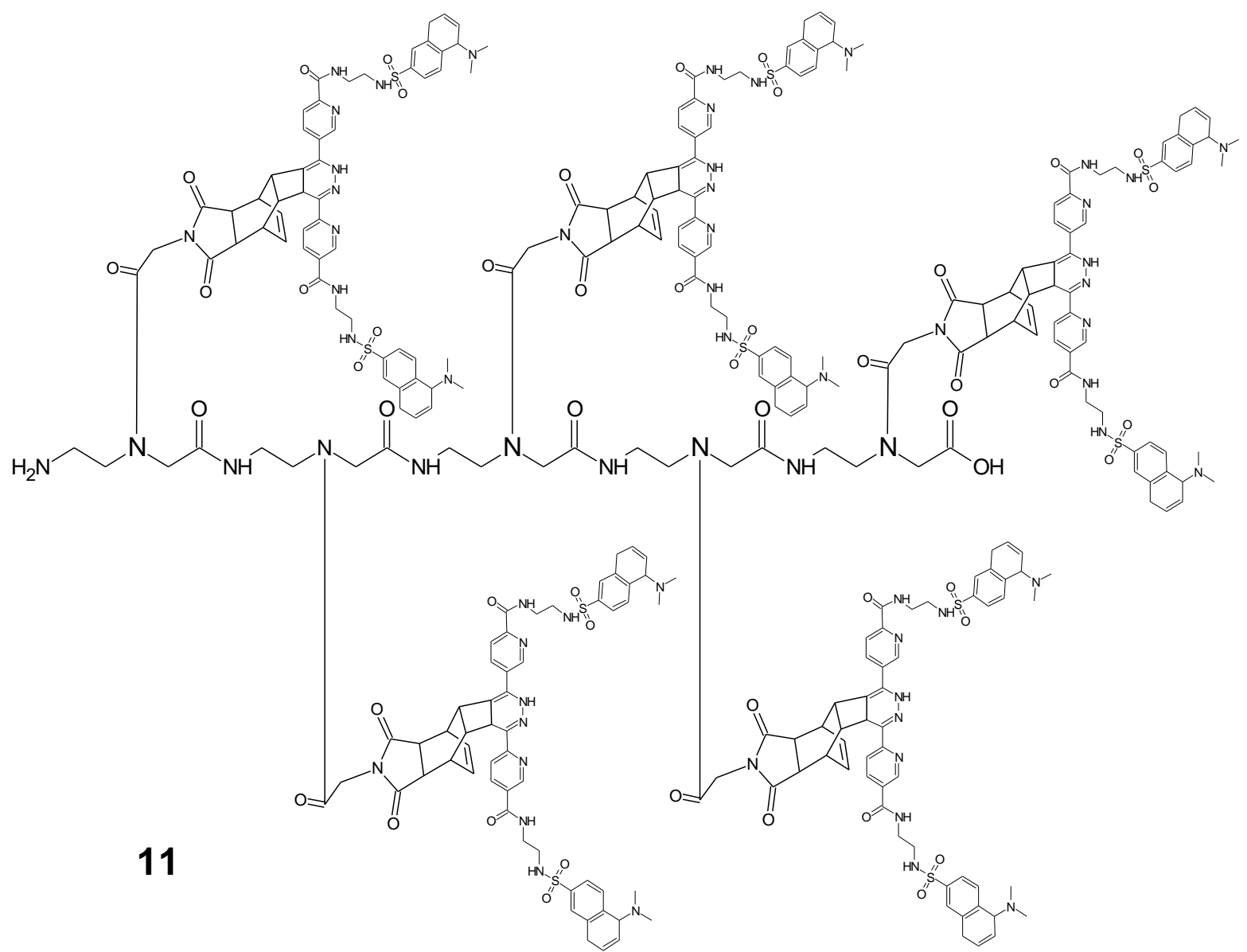

Figure 6 shows the ligation product 11 of the polyamide pentamer 8 after the complete $D_{A R} R_{\text {inv }}$ reaction with the diene compound dimethyl-1,2,4,5-tetrazine-3,6-dicarboxylate derivatized with the fluorescent dye dansyl chloride [5-(dimethylamino)naphthalene-1-sulfonyl chloride] connected with an ethylene diamine linker. 


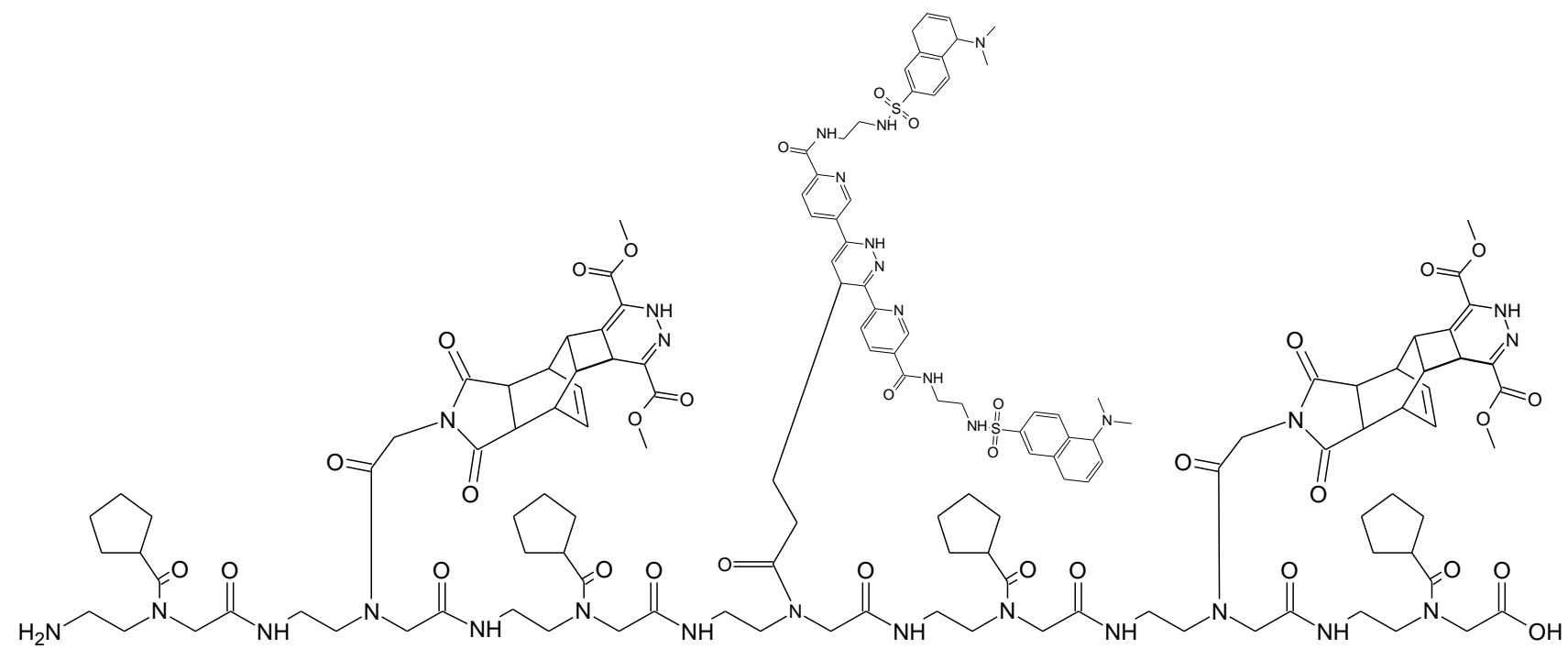

12

Figure 7 shows the ligation product 12 of the polyamide heptamer molecule (in two-steps generated as described in the material and methods section): first ligation step (A) with the Reppe Anhydride derivative acting as dienophile and the dimethyl-1,2,4,5-tetrazine-3,6-dicarboxylate as diene component. The second ligation step (B) was the reaction of pentenoic acid group with the tetrazine, two fold dansyl functionalized (symmetrical molecule). Avoiding sterical interactions which can hamper the ligation processes all dienophile compounds were spatially separated with an amide-based monomer functionalized with a cyclopentane group 2.

\section{Further examples of functionalizations}

Ligation of the pentenoic acid pentamer with the dimethyl-1,2,4,5-tetrazine-3,6-dicarboxylate.

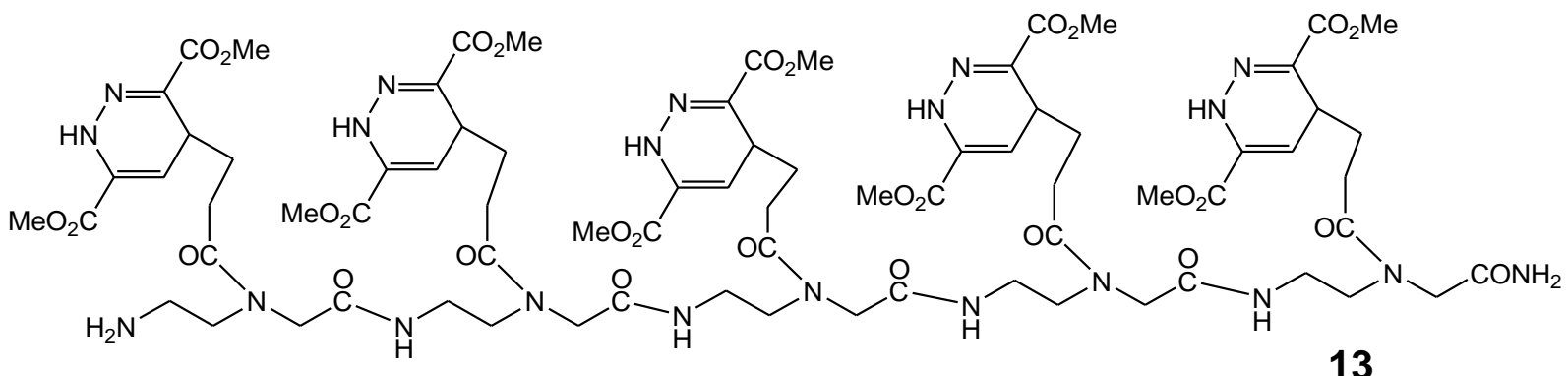

Figure 8 describes the reaction product of $\mathbf{1 3}$ after chemical ligation by the $\mathrm{DAR}_{\mathrm{inv}}$ of the pentamer consisting of five pentenoic acid monomers 2 synthesized by SPPS as a dienophile reaction partner and with the dimethyl 1,2,4,5-tetrazine-3,6-dicarboxylate as the diene component. 
Ligation of the polyamide pentenoic acid pentamer with the dimethyl-1,2,4,5-tetrazine-3,6dicarboxylate dansyl derivatized.

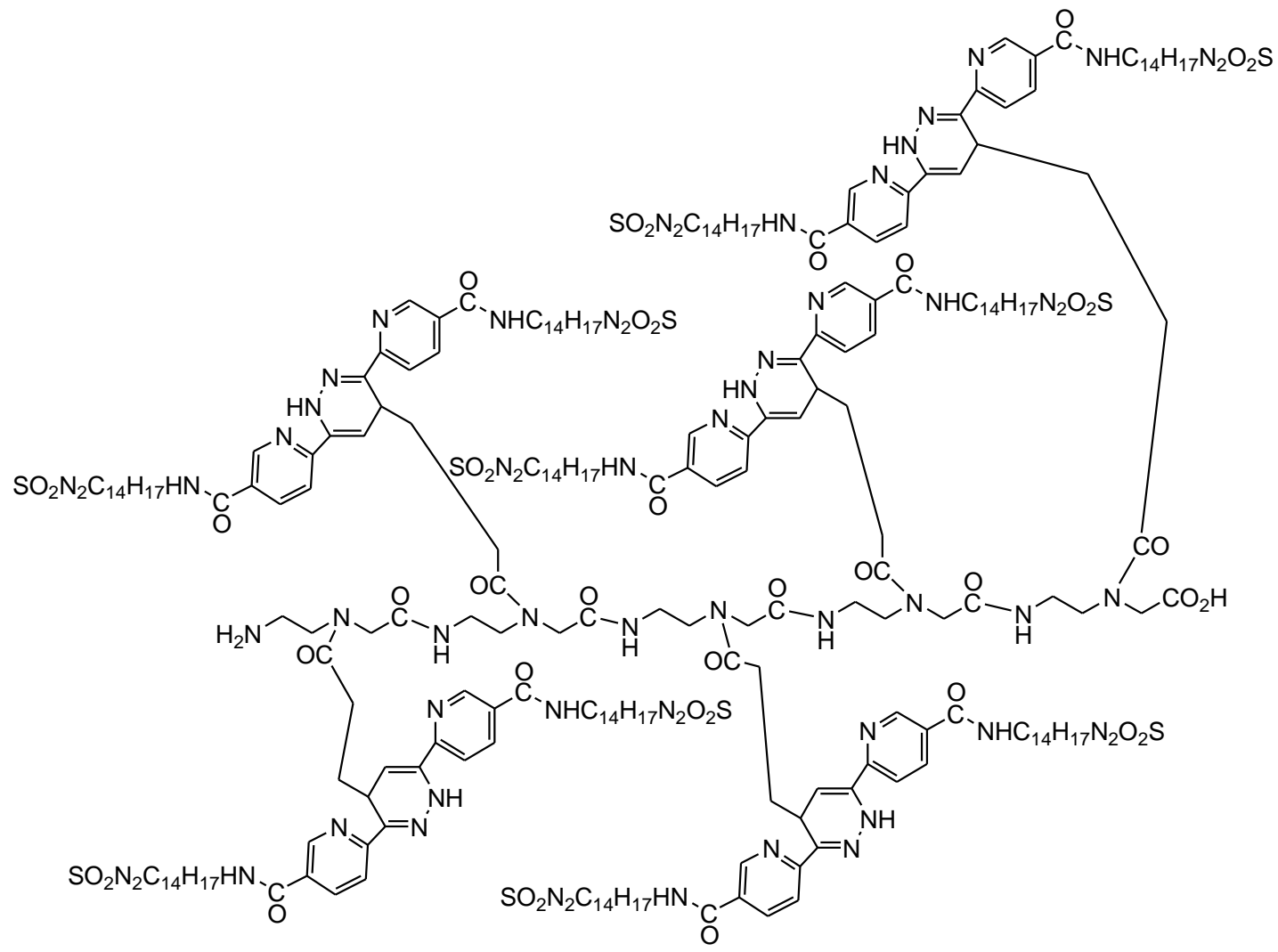

14

Figure 9 elucidates the product of 14 after the complete $D A R_{\text {inv }}$-based ligation of the penta-amide (pentenoic acid building blocks) as a dienophile component with five diene molecules of dimethyl-1,2,4,5-tetrazine-3,6-dicarboxylate which are dansyl derivatized 7.

\section{Discussion}

Efforts were made in the development of chemoselective ligation reactions resulting in multi-faced coupling methods which are documented by Hermanson [24]. For future "Click Chemistry" applications the rapid and selective ligations must fulfill dedicated requirements e.g. to be useful in living systems, generating stable educts, intermediates, and products in order to answer questions about in vivo protein localizations and interactions as well as about cell trafficking and migration activity of stem cells for instance. The Staudinger ligation is broadly considered as an eligible candidate living up to expectations [25-27]. Here we used for such selective reactions the Diels Alder Reaction with inverse electron demand $\left(D R_{\text {inv }}\right)$ which seems to be predestinated $[15,28]$.
The design of different polyamides composed of the "PNA" like amide backbone whose nucleobase is substituted with components suitable for $\mathrm{DAR}_{\text {inv }}$ ligation chemistry was established in our group and is described in the methods part.

The broad spectrum of these ligation reactions is possible by the optional exchange of building blocks which in turn can be functionalized ready for Click Chemistry according to production requirements. The new molecules were functionalized, as dienophile- or diene compounds by coupling to the glycine's $\mathrm{N}$-terminus, as originally described by Nielsen in the protocols for the synthesis of the peptide nucleic acid (PNA) backbone [29, 30].

We synthesized and investigated ligations of active components e.g. the tetracyclo$\left[5.4 .2^{1,7} \cdot \mathrm{O}^{2,6} \cdot \mathrm{O}^{8,11}\right] 3,5$-dioxo-4-aza-9,12-tridecadien, well known as "Reppe Anhydride" [16] which is con- 
sidered as a suitable candidate for the ligation reaction with $\mathrm{DAR}_{\text {inv }}$. The synthesis's steps as well as the chemical reactions were documented in 2009 by the Pipkorn group [31].

In this paper we focused our studies at first to the synthesis of the amide pentamer functionalized with the Reppe Anhydride 8 (Figure 3). In this context it is also important to note that the used Fmoc-protected building block derivatives (Figure 1) like 3 can avoid both: I) an unnecessary molecule expansion after ligation with projected functional molecules and associated undesired reactions and II) steric effects.

Furthermore, with all these functionalized amide monomers, Fmoc-protected (Figure 1), the polyamide synthesis can be carried out by use of the established solid phase peptide synthesis (SPPS). Unnecessary coupling steps can be circumvented and the corresponding products can be achieved in satisfactorily yields and in good quality.

The Figure 1 illustrates three building blocks whereof $\mathbf{2}$ and $\mathbf{3}$ are functionalized with dienophiles featuring different chemical reactivity, $\mathbf{1}$ was functionalized with the inactive cyclopentane in order to act as a "spacer" compound avoiding spatial sterical interactions which could hamper the ligation reaction.

A descriptive example for the synthesis of polymers offering the variability for independent ligation reactions based on the $\mathrm{DAR}_{\text {inv }}$ with dienophile groups with different chemical reactivity is illustrated in Figure 7, which represents the reaction product after the independent ligations $\mathbf{A}$ and $\mathbf{B}$ by $\mathrm{DAR}_{\text {inv }}$ in $\mathbf{1 2}$. It shows the structural formula of the amide heptamer, functionalized with four building blocks, which possess a cyclopentane group 1, which in turn separates the two monomers featuring the Reppe Anhydride $\mathbf{3}$ and the monomer with the pentenoic acid 2 in the center of the heptamer.

The $\mathrm{DAR}_{\text {inv }}$ based Click chemistry's potential is high. It allows to ligate user-defined components for imaging and/or for therapy with PNA like amide based building blocks. These examples may contribute to the establishment of a platform for expanded use in future pharmaceutical applications. In this respect positive results of toxicologic studies are indispensable to qualify such components as candidates for cell- and tissue specific therapeutic approaches. They are also ideal as diagnostic tools in the increasing fields of the patient-specific therapy and in imaging of metabolic processes at the cellular level [5, 15, $23,32]$. In summary, it is fair to say, that further efforts in the development of new functional building blocks could enhance the diversity in the ligation chemistry. They also can be conductive for both for sustainable solutions in the pharmaceutical science as discussed by Kummerer [33] and in the strongly growing field of the theranostics [34].

\section{Conflict of Interest}

The authors have declared that no conflict of interest exists.

\section{References}

1. Bachmann WE, Chemerda JM. The Diels Alder Reaction of 1-Vinyl-6-Methoxy-3,4-Dihydronaphthalene with Citraconic Anhydride. J Americ Chem Soc. 1948; 70: 1468-73.

2. Alder K, Diels O. [Otto Diels and Kurt Alder; winners of the Nobel Prize in chemistry.]. Cienc Invest. 1951; 7: 143-4.

3. Stocking EM, Williams RM. Chemistry and biology of biosynthetic Diels-Alder reactions. Angew Chem Int Ed Engl. 2003; 42: 3078-115.

4. Blackman ML, Royzen M, Fox JM. Tetrazine ligation: fast bioconjugation based on inverse-electron-demand Diels-Alder reactivity. J Am Chem Soc. 2008; 130: 13518-9.

5. Waldeck W, Wiessler M, Ehemann V, et al. TMZ-BioShuttle--a reformulated temozolomide. Int J Med Sci. 2008; 5: 273-84.

6. Ibrahim-Ouali M. Diels-Alder route to steroids and associated structures. Steroids. 2009 Feb;74(2):133-62.

7. Carboni RA, Lindsey RV. Reactions of Tetrazines with Unsaturated Compounds - A New Synthesis of Pyridazines. J Americ Chem So. 1959; 81: 4342-6.

8. Nielsen PE. Peptide Nucleic-Acid (PNA) a Structural DNA Mimic. Prog Biophys Mol Biol. 1996; 65: SB103.

9. Stein CA, Mori K, Loke SL, et al. Phosphorothioate and normal oligodeoxyribonucleotides with 5'- linked acridine: characterization and preliminary kinetics of cellular uptake. Gene. 1988; 72: 333-41.

10. Johansson HE, Belsham GJ, Sproat BS, et al. Target-specific arrest of mRNA translation by antisense 2'-O-alkyloligoribonucleotides. Nucleic Acids Res. 1994; 22: 4591-8.

11. Heidenreich O, Gryaznov S, Nerenberg M. RNase H-independent antisense activity of oligonucleotide N3 '-- > P5 ' phosphoramidates. Nucleic Acids Res. 1997; 25: 776-80.

12. Egholm $M$, Nielsen PE, Buchardt $\mathrm{O}$, et al. Recognition of Guanine and Adenine in DNA by Cytosine and Thymine Containing Peptide Nucleic-Acids (PNA)(1,2). J Amer Chem Soc. 1992; 114: 9677-8.

13. Summerton J, Weller D. Morpholino antisense oligomers: design, preparation, and properties. Antisense Nucleic Acid Drug Dev. 1997; 7: 187-95.

14. Koshkin AA, Nielsen P, Meldgaard M, et al. LNA (locked nucleic acid): An RNA mimic forming exceedingly stable LNA : LNA duplexes. Journal of the American Chemical Society. 1998; 120: 13252-3.

15. Wiessler M, Waldeck W, Pipkorn R, et al. Extension of the PNA world by functionalized PNA monomers eligible candidates for inverse Diels Alder Click Chemistry. Int J Med Sci. 2010; 7: 213-23.

16. Reppe $\mathrm{W}$, Schlichting $\mathrm{O}$, Klager $\mathrm{K}$, et al. Cyclisierende Polymerisation von Acetylen I. Justus Liebigs Annalen der Chemie. 1948; 560: 1-92.

17. Atherton E, Sheppard RC. In: Undenfriend S, Meienhofer J, editors. The Peptides. Orlando: Academic Press 1987:1-38.

18. Thomson SA, Josey JA, Cadilla R, et al. Fmoc Mediated Synthesis of Peptide Nucleic-Acids. Tetrahedron. 1995; 51: 6179-94.

19. Morrison CJ, Park SK, Simocko C, et al. Synthesis and characterization of fluorescent displacers for online monitoring 
of displacement chromatography. J Am Chem Soc. 2008; 130: 17029-37.

20. Merriefield RB. Solid Phase Peptide Synthesis. I The Synthesis of a Tetrapeptide. J Americ Chem Soc. 1963; 85: 2149-54.

21. Carpino LA, Han GY. The 9-Fluorenylmethoxycarbonyl Amino-Protecting Group. J ORG CHEM. 1972; 37: 3404-9.

22. Boger DL, Coleman RS, Panek JS, et al. A detailed, convenient preparation of dimethyl 1,2,4,5-tetrazine-3,6-dicarboxylate. J Org Chem. 1985; 50: 5377-9.

23. Wiessler $M$, Waldeck $W$, Kliem $C$, et al. The Diels-Alder-reaction with inverse-electron-demand, a very efficient versatile click-reaction concept for proper ligation of variable molecular partners. Int J Med Sci. 2009; 7: 19-28.

24. Hermanson GT. Bioconjugate Techniques. San Diego CA: Academic Press; 2008: 1-1202.

25. Kiick KL, Saxon E, Tirrell DA, et al. Incorporation of azides into recombinant proteins for chemoselective modification by the Staudinger ligation. Proc Natl Acad Sci U S A. 2002; 99: 19-24.

26. Lin FL, Hoyt HM, van $\mathrm{HH}$, et al. Mechanistic investigation of the staudinger ligation. J Am Chem Soc. 2005; 127: 2686-95.

27. Yeo DS, Srinivasan R, Chen GY, et al. Expanded utility of the native chemical ligation reaction. Chemistry. 2004; 10: 4664-72.

28. Sauer J, Wiest H. Diels-Alder-Additionen Mit Inversem Elektronenbedarf. Angewandte Chemie-International Edition. 1962; 74: 353.

29. Nielsen PE, Egholm M, Berg RH, et al. Sequence-selective recognition of DNA by strand displacement with a thymine-substituted polyamide. Science. 1991; 254: 1497-500.

30. Nielsen PE. Peptide nucleic acids (PNA) in chemical biology and drug discovery. Chem Biodivers. 2010; 7: 786-804.

31. Pipkorn R, Waldeck W, Didinger $B$, et al. Inverse-electron-demand Diels-Alder reaction as a highly efficient chemoselective ligation procedure: Synthesis and function of a BioShuttle for temozolomide transport into prostate cancer cells. J Pept Sci. 2009; 15: 235-41.

32. Braun K, Dunsch L, Pipkorn R, et al. Gain of a 500-fold sensitivity on an intravital MR contrast agent based on an endohedral gadolinium-cluster-fullerene-conjugate: a new chance in cancer diagnostics. Int J Med Sci. 2010; 7: 136-46.

33. Kummerer $K$. The presence of pharmaceuticals in the environment due to human use--present knowledge and future challenges. J Environ Manage. 2009; 90: 2354-66.

34. Chen X. Integrin Targeted Imaging an Therapy. Theranostics. 2011; 1: 28-9. 